\title{
Relationships among Service Quality, Value, and Student Athlete Satisfaction at Taiwan's National Tug of War Competition
}

\author{
De-Jen Lee \\ Chang Gung University \\ E-Mail: passwn@mail.cgu.edu.tw \\ Li-Wen Hsieh \\ National Taipei University \\ E-Mail: hsielee@mail.ntpu.edu.tw \\ Eva (Hui-Ping) Cheng* \\ National Taipei University \\ E-Mail: evaping@gm.ntpu.edu.tw
}

\begin{abstract}
Service quality has been extensively used to improve corporate performance in business; however, few studies have applied this concept to the sports field. In Taiwan, students' sporting events play an important role in national sports development as they are the main channels in which to incubate elite athletes and a way to develop professional experiences related to holding mega-sports events. Therefore, the main purpose of this study is the application of the service quality concept to sports events. Specifically, a model was proposed to examine the relationships among service quality, perceived value, and satisfaction. Self-administered questionnaire surveys were completed by 356 student athletes recruited from the 2013 National Tug of War Competition in Taiwan. The data were analyzed using structural equation modeling with LISREL 8.52. Results of this study indicated that the research model fit the data well. Participants' overall satisfaction was directly influenced primarily by perception of event value, followed by staff service quality and interaction service quality; finally, the perceived event value served as a mediator, and significant indirect effects on participants' satisfaction were found in administrative service quality and facility service quality. The study established a model including service quality, value, and
\end{abstract}

* The Corresponding Author 
satisfaction for tug of war competitions. Suggestions for sports organizers and implications for future studies are provided.

Keywords: Service Quality; Perceived Event Value, Satisfaction, Tug of War Competitions

\section{INTRODUCTION}

Tug of war is a relatively new sport in Taiwan compared to sports such as track and field, baseball, and basketball. The country's formal tug of war competition started in 1997 (Lee \& Hsieh, 2011), and the sport has been promoted by Taiwan's Ministry of Education since the early 1990s due to its traditional teamwork spirit and its basic skill requirements. With the government's support, the Chinese Taipei Tug of War Association has made strong efforts to introduce these competitions at all school levels and to hold competition events for students. As a result, the sport has become increasingly popular at all school levels, and Taiwanese athletes have won the World Championship several times. Students' sporting events play an important role in the country. They are the main channel for incubating elite athletes, and they are a way to develop knowledge about holding even larger sporting events. There are six major national sporting events in Taiwan, and two of them are held for student athletes. Therefore, there is a need to understand the quality of sporting events for student athletes.

In the sports business, products or services are classified as core products and extension products (Li, Hofacre, \& Mahony, 2001; Mullin, Hardy, \& Sutton, 2016). Core sports products include (1) consumer participation in exercises or recreational or professional competition; and (2) spectators attending sports events and watching performances. Extension sport products depend on the existence of core products. For example, athletic shoes, apparel, sporting equipment, and coaching services are a consequence of people participating in sports, and sports-related broadcasting, marketing service, news, souvenirs, lottery, and online fantasy games are extension products of spectatorship. Therefore, core sport products are key factors in the success of the sports business, and a sporting event can generate these two core sports products.

The success of a sporting event is determined by the degree to which it satisfies participants/athletes and spectators/fans with quality service (Ko, Kim, Kim, \& Lee, 2010). This study focuses on participation - specifically, on athletes in a sporting event-because it is crucial to the event's success. For example, Venus Williams, a leading female tennis player, first participated in the WTA Taiwan Open in 2016. Her 
participation drew on average around 1,500 fans per day, which is two to three times more spectators than the previous year (Zeng, 2016). Williams was happy with her experience at the Taiwan Open and promised that she would attempt to convince her sister, Serena Williams, the highest ranked player in the world, to participate in the Taiwan Open the following year (Peng, 2016). What satisfies players or athletes and motivates them to participate in a sporting event? From a participant's point of view, service quality of a sporting event includes professional and well-organized competition settings, judges, schedules, staff, and other logistics. These factors influence a participant's perceived value of the event and the amount of time, money, and effort he or she is willing to expend to prepare for and take part in the event. Eventually, the service quality and value that an athlete perceives from the event may influence the participant's satisfaction and willingness to appear in future editions or promote the event. This study attempts to address specific service factors, degree of influence on service value and satisfaction, and the impact of demographic variables for a sporting event.

The main purpose of this study is to discern, among several service factors in a sporting event, which factors have the most significant influence on participants' perceived value and satisfaction. The study will also identify a path model among service quality, perception, and satisfaction. By setting a path model, moderation effects will be examined by gender, level, and experience.

\section{LITERATURE REVIEW}

Service quality has been used to improve corporate performance in businesses, such as in the retail, hotel, bank, and transportation industries. The SERVQUAL model proposed by Parasuraman, Zeithaml, and Berry (1988) is the most well-known and popular service quality concept in this field. It contains five service factors: tangibles, reliability, responsiveness, assurance, and empathy. However, studies have also found that the SERVQUAL model may not fit all types of businesses, and service factors can differ according to different industries (Cronholm \& Salomonson, 2014; Parasuraman \& Grewal, 2000). The discussion of service quality's influence on participation sports is relatively recent. Studies on sports events in Taiwan have found that major service quality includes special events, interaction, experience, environment, and information (Chen, Tsai, \& Ye, 2014; Yang, Tsai, \& Lin, 2014). Recent studies focusing on student athletes indicated that service factors may include the staff, facility, judges, experience, administration, information, procedure, and medical service (Lee, 2008; Lee \& Hsieh, 2011; Lee \& Hsieh, 2015). 
Perceived product or service value is a subjective perception that the consumer assesses by noting an overall utility of a product or service based on what is received and what is given (Petrick, 2002; Tu, Li, \& Chih, 2013). Value is also an influential factor that leads to product- or service-purchasing and referral behaviors. Zeithaml (1988), the pioneer researcher of perceived value, defined four diverse meanings of value: (1) value is low price; (2) value is whatever one wants in a product; (3) value is the quality that the customer received for the price paid; and (4) value is what the customers get for what they give. Based on Zeithaml's definition, a common measure of a product's or service's perceived value was developed based on five factors: quality, emotional response, monetary price, behavioral price, and reputation (Hightower, Brady, \& Baker, 2002; Petrick, 2002; Tu et al., 2013). Recent studies have explored participants' perceived value of a sporting event. One research evaluated perceived value based on esteem/escapism, economy, social, service, entertainment, and aesthetics of a sporting event (Musa \& Kassim, 2013). Another utilized the aforementioned five factors of measurement to analyze a sport participant's perceived value (Lu, Lee, Tsai, \& Lin, 2013; Yang et al., 2014).

Satisfaction, an important research area in business, is the consumer's overall feeling after using a product or accepting a service that leads to repurchase and referral intentions (Ledden, Kalafatis, \& Mathioudakis, 2011; Suharto \& Sulistiyono, 2015; Yu et al., 2014). The ways to measure a consumer's satisfaction are diverse. Some researchers have used a single-item model to understand a customer's overall satisfaction with a product or service (Bigne, Sanchez, \& Sanchez, 2001; Suharto \& Sulistiyono, 2015), and others have suggested multi-dimensional measurements to evaluate satisfaction (Ko et al., 2010; Millan \& Esteban, 2004; Yu et al., 2014). Similarly, measures of sport participants' satisfaction with sporting events have also utilized either a single-item method (Chen et al., 2014; Lin, Chang, \& Su, 2007; Murray \& Howat, 2002; Tsuji, Bennett, \& Zhang, 2007) or a multi-factor method (Yang et al., 2014; Yoshida \& James, 2010). Nevertheless, the questions asked in multi-dimensional satisfaction scales are somewhat the same as questions asked in a service quality scale. For researchers to understand product or service quality and consumer satisfaction, the use of multi-factor satisfaction scales may cause an overestimated correlation between these two variables.

When discussing the relationships among service quality, perceived value, and satisfaction, researchers have suggested that corporations try to increase consumers' perceived value by promoting service quality, which leads to higher satisfaction (Bawa, Gupta, \& Sharma, 2013; Ledden et al., 2011; Yu et al., 2014; Zeithaml, 1988). Past research in the business field has adopted service quality as a precedent to 
perceived value and satisfaction as well as perceived value as a mediator between service quality and satisfaction (Chuang, Chen, \& Chen, 2010; He \& Li, 2011; Hightower et al., 2002; Ledden et al., 2011; Yu et al., 2014). Studies in sports have found that service quality positively influences both perceived value and satisfaction (Chen et al., 2014; Lee \& Hsieh, 2011; Lin et al., 2007; Lu et al., 2013; Murray \& Howat, 2002; Yang et al., 2014), perceived value positively influences satisfaction (Lin et al., 2007; Lu et al., 2013; Murray \& Howat, 2002; Yang et al., 2014), and perceived value has a mediating effect (Lin et al., 2007; Murray \& Howat, 2002). As a result, the study's conceptual model is presented in Figure 1. Bivariate correlations and the overall relationship model among the three variables have been analyzed in previous studies. However, the nature of service quality is multi-faceted, and a corporation may have more interest in finding key or influential service factors and different service reactions among different populations. Thus, the current study proposes the following hypotheses:

$\mathrm{H}_{1}$ : Service quality has a directly positive effect on perceived value.

$\mathrm{H}_{2}$ : Service quality has a directly positive effect on satisfaction.

$\mathrm{H}_{3}$ : Perceived value has a directly positive effect on satisfaction.

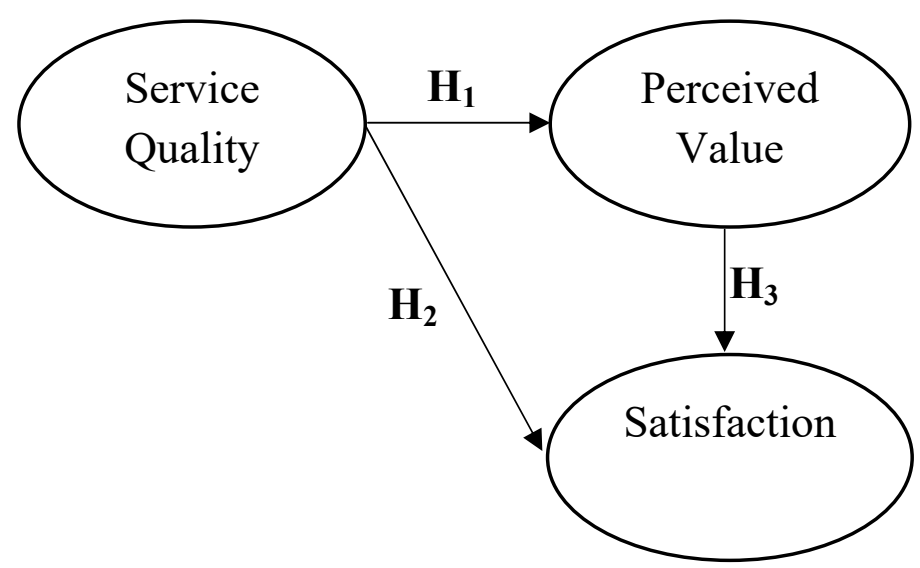

Figure 1 Conceptual Model of the Study

\section{Participants}

\section{METHOD}

The participants of this study were selected from the 2013 National Tug of War Competition. Student athletes were asked to fill out the questionnaires during a break in the competition. Four hundred questionnaires were distributed, and $356(89 \%)$ were determined to be valid. Participants' mean age was 16.45 years old $(\mathrm{SD}=2.24)$ and 
most of them were male (74\%), high school students $(77 \%)$, in the division I level (69\%), and not in their first experience participating in a competition (65\%).

\section{Measures}

The event service quality scale was modified from Lee and Hsieh's (2011) study. The scale included 21 items and 7 services subscales (staff, facility, judge, experience, administration, information, and medication). A 1-factor and 5-item scale measuring student athletes' perception of the event's value was in accordance with previous research (Hightower et al., 2002). The student athletes' satisfaction was measured with reference to the concept of overall satisfaction (Murray \& Howat, 2002). Five-point rating scales were used for all measurement scales.

\section{Data Analysis}

SPSS 17.0 was used for descriptive statistics and reliability analysis. LISREL 8.52 was utilized to conduct validity, structural model, and moderating effect analyses. The study used a backward selection method to identify influential event service factors. The insignificant path coefficients were then removed, starting with the lowest $t$-value score. The steps continued until all path coefficients in the model were significant. The study examined moderating effects by applying a multiple group analysis (Jaccard \& Wan, 1996). The participants were divided into two groups based on their respective medians. Multiple group SEM analysis was used to identify the existence of moderating effects.

\section{RESULTS}

\section{Validity and Reliability of Scales}

Table 1 shows that the mean scores of event service items ranged from 3.36 to 4.02. The Experience Service subscale showed a highest mean score $(M=3.99)$ while the Facility Service subscale showed the lowest score $(\mathrm{M}=3.52)$. The mean scores of perceived event value ranged from 3.76 to 3.88 , and on average, participants' overall event satisfaction was 3.96 .

Confirmatory factor analysis indicated that the measure model fit the data well $\left(\chi_{(271)}^{2}=393.46, p<.05, \chi^{2} / d f=1.45, \mathrm{RMSEA}=.036, \mathrm{NNFI}=.98, \mathrm{CFI}=.98, \mathrm{SRMR}\right.$ $=.045, \mathrm{GFI}=.87, \mathrm{AGFI}=.83)$. Convergent validity was evident as all factor loadings were significant $(p<.05)$. The internal consistency reliability of the scales was high, with Cronbach's alpha ranging from .83 to .93 . The AVE scores ranged from .66 to .72 , also indicating good construct reliability. 
Table 1 Descriptive Statistic, Validity, and Reliability of Measurement

\begin{tabular}{|c|c|c|c|c|c|}
\hline Factor/Item & $M$ & $S D$ & $\lambda$ & $\alpha$ & AVE \\
\hline \multicolumn{6}{|l|}{ Event Service Quality Scale } \\
\hline Staff & 3.93 & 0.78 & & .85 & .66 \\
\hline 1. Staff are very friendly. & 4.01 & 0.87 & .75 & & \\
\hline 2. Staff respond to my requests promptly. & 3.88 & 0.91 & .84 & & \\
\hline 3. Staff are competent. & 3.89 & 0.89 & .84 & & \\
\hline Facility & 3.52 & 1.02 & & .86 & .67 \\
\hline 4. The event surrounding environment is visually appealing. & 3.62 & 1.12 & .81 & & \\
\hline 5. The stadium is well-designed. & 3.36 & 1.24 & .84 & & \\
\hline 6. This event has standard facilities and equipment. & 3.56 & 1.11 & .80 & & \\
\hline Medical Support & 3.87 & 0.81 & & .86 & .67 \\
\hline 7. Medical service and facilities are well-prepared. & 3.81 & 0.97 & .82 & & \\
\hline 8. Medical staff are professional. & 3.90 & 0.89 & .86 & & \\
\hline 9. Medical staff are friendly. & 3.90 & 0.90 & .77 & & \\
\hline Judge & 3.84 & 0.90 & & .88 & .72 \\
\hline 10. Judges are professional. & 3.78 & 1.00 & .82 & & \\
\hline 11. Judges are fair and impartial. & 3.85 & 1.00 & .91 & & \\
\hline 12. Competition rules are fair and reasonable. & 3.89 & 1.00 & .82 & & \\
\hline Administration & 3.91 & 0.78 & & .83 & .65 \\
\hline 13. Competition schedule is well controlled. & 3.92 & 0.94 & .66 & & \\
\hline 14. Easy registration procedure. & 3.89 & 0.87 & .82 & & \\
\hline 15. Check-in procedure is efficient. & 3.91 & 0.89 & .91 & & \\
\hline Information & 3.79 & 0.83 & & .89 & .72 \\
\hline 16. Easy to contact the organizer. & 3.80 & 0.93 & .85 & & \\
\hline $\begin{array}{l}\text { 17. Easy to contact the organizer via its website's message } \\
\text { board. }\end{array}$ & 3.75 & 0.92 & .85 & & \\
\hline 18. The website provides up-to-date information. & 3.81 & 0.91 & .85 & & \\
\hline Interaction & 3.99 & 0.80 & & .87 & .70 \\
\hline 19. I get to interact with other people & 4.01 & 0.88 & .89 & & \\
\hline 20. I get to meet up with other student athletes. & 3.96 & 0.91 & .86 & & \\
\hline 21. I have a great experience during the competition. & 4.02 & 0.91 & .75 & & \\
\hline Perceived Event Value Scale & & & & .93 & .72 \\
\hline 1. Quality of the event is reliable. & 3.82 & 0.88 & .84 & & \\
\hline 2. Participation in this event makes me feel happy. & 3.88 & 0.94 & .82 & & \\
\hline 3. The event is worthwhile to spend time. & 3.80 & 0.96 & .87 & & \\
\hline 4. All event services are cost-effective. & 3.76 & 0.95 & .81 & & \\
\hline 5. The event has a great reputation. & 3.87 & 0.93 & .89 & & \\
\hline Overall Event Satisfaction & 3.96 & 1.03 & -- & -- & -- \\
\hline
\end{tabular}

$\lambda$ : factor loading; $\alpha$ : Chronbach's $\alpha$; AVE: Average Variance Extracted 


\section{Baseline Model and Influential Service Factors}

A structural equation model analysis was conducted to examine the relationship among service factors, perceived event value, and satisfaction. After deleting insignificant paths using the backward selection method, four service factors were retained in the model. The baseline model was found to fit the data well $\left(\chi_{(299)}^{2}=\right.$ $445.16, p<.05, \chi^{2} / d f=1.49, \mathrm{RMSEA}=.037, \mathrm{NNFI}=.98, \mathrm{CFI}=.98, \mathrm{SRMR}=.045$, GFI $=.86$, AGFI $=.82$ ). Overall, the model explained $74 \%$ of the variances of perceived event value and $61 \%$ of event satisfaction. Participants' overall satisfaction was directly influenced primarily by their perception of event value $(\beta=.57)$ followed by staff service quality $(\beta=.14)$ and interaction service quality $(\beta=.13)$. Perceived event value was explained by administrative service quality $(\beta=.61)$ and facility service quality $(\beta=.33)$. The perceived event value served as a mediator, and significant indirect effects on event satisfaction were found in administrative service quality $(\beta=.35)$ and facility service quality $(\beta=.19)$.

Table 2 Direct and Indirect Effects of Path Coefficients

\begin{tabular}{llc}
\hline Path & $\beta$ & $t$ \\
\hline Direct Effect & & \\
Perceived Event Value $\rightarrow$ Event Satisfaction & .57 & $7.84^{*}$ \\
Staff $\rightarrow$ Event Satisfaction & .14 & $2.00^{*}$ \\
Interaction $\rightarrow$ Event Satisfaction & .13 & $2.05^{*}$ \\
Administration $\rightarrow$ Perceived Event Value & .61 & $8.75^{*}$ \\
Facility $\rightarrow$ Perceived Event Value & .33 & $4.70^{*}$ \\
\hline Indirect Effect & \multicolumn{3}{|}{} \\
Administration $\rightarrow$ Event Satisfaction & .35 & $5.52^{*}$ \\
Environment $\rightarrow$ Event Satisfaction & .19 & $4.01^{*}$ \\
\hline$\beta$. standardized path coefficient $* *<05$ & &
\end{tabular}

\section{Moderation Effect}

Moderation effects were analyzed on the model path coefficient by gender, level, and participation experience. A two-sample structural equation model analysis was conducted. The baseline model was first established with model coefficients of two samples, all of which were estimated freely. A restricted model was then set, with two samples' path coefficients forced to be equal. If the inflation of the chi-square score was significant, the moderation effect existed by testing the variable. Table 3 shows that moderation effects were not found in the model by gender $\left(\Delta \chi^{2}=7.81, \Delta d f=5, p\right.$ $>.05)$, level $\left(\Delta \chi^{2}=4.64, \Delta d f=5, p>.05\right)$, or participation experience $\left(\Delta \chi^{2}=8.6, \Delta d f\right.$ $=5, p>.05)$. 
Table 3 Moderation Effect by Gender, Level, and Participation Experience

\begin{tabular}{|c|c|c|c|c|c|c|}
\hline \multirow[b]{2}{*}{ Moderator } & \multicolumn{2}{|c|}{ Free Model } & \multicolumn{2}{|c|}{ Restricted Model } & \multirow[b]{2}{*}{$\Delta \chi^{2}$} & \multirow[b]{2}{*}{$\Delta d f$} \\
\hline & $\chi^{2}$ & $d f$ & $\chi^{2}$ & $d f$ & & \\
\hline Gender & 1501.29 & 598 & 1509.10 & 603 & $7.81^{\text {n.s. }}$ & 5 \\
\hline Level $^{\mathrm{a}}$ & 1418.35 & 598 & 1422.99 & 603 & $4.64^{\text {n.s. }}$ & 5 \\
\hline Experience $^{\mathrm{b}}$ & 1278.55 & 598 & 1287.15 & 603 & 8.60 n.s. & 5 \\
\hline
\end{tabular}

a. Level includes 2 groups: division I and division II

b. Experience includes 2 groups: low experience and high experience n.s.: nonsignificant

\section{DISCUSSION AND CONCLUSION}

Discussions of individual factors' influences on service quality have been found in business research ( $\mathrm{He} \& \mathrm{Li}, 2011$; Ledden et al., 2011); however, it is a relatively new topic in the sports business field (Lee \& Hsieh, 2015). Among seven service quality factors, significant influences were found in the model only in the factors of administration, facility, staff, and interaction. Participants' perceptions of events' value were explained by administration and facility service qualities, and overall event satisfaction was determined by perceived value, staff service quality, and interaction service quality. These results are different from the findings from Lee and Hsieh's (2015) study on Intercollegiate Athlete Games, in which the judge, facility, information, and medical support service qualities were found to be influential in the model. The reason may be that the Intercollegiate Athlete Games is a larger sporting event, which includes multi-sport competitions other than the National Tug of War Competition, which is a single-sport event. The discovery of facility service quality's important influence in sporting events is consistent with previous studies (Lee, 2008; Lee \& Hsieh, 2015). However, administration service quality is more important than facility service quality for tug of war competitions in terms of impacting perceived value.

As with previous studies, perceived value is the most important factor influencing student athlete satisfaction (Lee \& Hsieh, 2015). Dissimilarly, medication service quality is not found to be influential on satisfaction. Instead, for tug of war competitions, athletes' satisfaction can be affected by staff service quality and the quality of interaction with other athletes. This may be because interaction with event staff and other athletes occurs more often during these competitions.

The data in the current study indicated that perceived event value served as a mediator when explaining event participation satisfaction through administration and facility service qualities. Past research has found that perceived value has either a completely mediating effect $(\mathrm{He} \& \mathrm{Li}, 2011)$ or a partial mediation effect (Chuang et 
al., 2010; Ledden et al., 2011) upon the explanation of satisfaction. The current study found that service factors explained satisfaction either with a complete mediation effect upon perceived value or without going through a mediator.

Past research has indicated that student athletes' perceived service quality can differ based upon demographic variables (Lee \& Hsieh, 2011), and moderation effects may exist in the relationship among service quality, event value, and satisfaction (Lee $\&$ Hsieh, 2015). However, our study found no significant moderation effect on the model based on gender, level, or experience. Unlike Lee and Hsieh's (2015) study on the Intercollegiate Athlete Games, our student athletes were from a single sport (i.e., tug of war). It may be that the nature of these competitions or the fact that this is a relatively new sport in Taiwan accounts for the findings with no moderation effect.

Facility service quality is consistently and undoubtedly a key factor for sporting events. A tug of war event organizer should prepare a competition's ground surface and rope to meet the Tug of War International Federation's requirements so that student athletes are not injured and are able to adapt to the international competition settings. In addition, facilities in the preparation area, practice space, and resting rooms should also meet athletes' needs. A tug of war competition event regularly involves more than 6 levels, 90 teams, and 800 competitors. Unfriendly registration procedures, delays, and inefficient competition scheduling could hinder athlete performance. Therefore, the administration service quality is important for this sport. An organizer must focus on the schedule and procedure for registration, check-in, and competition sequence.

\section{LIMITATIONS AND FUTURE STUDIES}

The current study initially established a relationship model including service quality, value, and satisfaction for tug of war competitions. Measurements were adapted from previous studies; however, one item of the service quality scale might have resembled the concept of satisfaction or the content of service value, which might have inflated the relationship among variables. Longitudinal studies may be conducted in the future to examine the consistency of the model. Future researchers could conduct in-depth inquiries of participants for further understanding as to how and why these service qualities play such influential roles. As a result, organizers could establish more specific tactics to improve a tug of war event's quality. 


\section{REFERENCES}

Bawa, P., Gupta, B. L., \& Sharma, B. (2013). Retail service quality's impact on value delivery \& customer satisfaction in a retail store environment. Journal of Marketing \& Communication, 9(1), 37-43.

Bigne, J. E., Sanchez, M. I., \& Sanchez, J. (2001). Tourism image, evaluation variables and after purchase behavior: Inter-relationship. Tourism Management, 22(6), 607-616. http://dx.doi.org/10.1016/s0261-5177(01)00035-8

Chen, M., Tsai, H., \& Ye, Y. (2014). Application of multilevel linear modeling for perceived service quality at a sport mega-event. Journal of Taiwan Society for Sport Management, 14(1), 1-25. http://dx.doi.org/10.6547/tassm.2014.0001 (In Chinese)

Chuang, Y. C., Chen, H. B., \& Chen, Y. J. (2010). The relationships among service quality, perceived value, satisfaction: A case of Sitou Nature Education Area. Journal of Island Tourism Research, 3(3), 45-62. (In Chinese)

Cronholm, S., \& Salomonson, N. (2014). Measures that matters: Service quality in IT service management. International Journal of Quality and Service Sciences, 6(1), 60-76. http://dx.doi.org/10.1108/IJQSS-12-2012-0022

He, H., \& Li, Y. (2011). Key service drivers for high-tech service brand equity: The mediating role of overall service quality and perceived value. Journal of Marketing Management, 27(1-2),

77-99. http://dx.doi.org/10.1080/0267257x.2010.495276

Hightower, R., Brady, M. K., \& Baker, T. L. (2002). Investigating the role of the physical environment in hedonic service consumption: An exploratory study of sporting events. Journal of Business Research, 55(9), 697-707. http://dx.doi.org/10.1016/s0148-2963(00)00211-3

Jaccard, J., \& Wan, C. K. (1996). LISREL analyses of interaction effects in multiple regression. Newbury Park, CA: Sage.

Ko, Y. J., Kim, Y. K., \& Lee, J. H. (2010). The role of involvement and identification on event quality perceptions and satisfaction: A case of US Taekwondo Open. Asia Pacific Journal of Marketing and Logistics, 22(1), 25-39. http://dx.doi.org/10.1108/13555851011013137

Ledden, L., Kalafatis, S. P., \& Mathioudakis, A. M. (2011). The idiosyncratic behavior of service quality, value, satisfaction, and intention to recommend in higher education: An empirical examination. Journal of Marketing Management, 21(11-12), 1232-1260. http:/dx.doi.org/10.1080/0267257x.2011.611117 
Lee, D. J., \& Hsieh, L.W. (2011). The development of a perceived event service quality scale for a student athlete tug-of-war competition. Journal of TASSM, 11(4), 297-315. (In Chinese)

Lee, D. J, \& Hsieh, L. W. (2015). The influence of service quality on perceived value and participation satisfaction for Intercollegiate Athlete Games. NTU Journal of Physical Education, 28, 67-77. (In Chinese)

Lee, S. C. (2008). A study of framework developing in facility service needs of multifunction gymnasiums: Take the 2008 National Intercollegiate Athlete Game for example. Journal of Leisure and Recreation Industry Management, 1(3), 15 28. (In Chinese). http://dx.doi.org/10.6213/JLRIM.2008.1(3)2

Li, M., Hofacre, S., \& Mahony, D. (2001). Economics of sport. Morgantown, WV: Fitness Information Technology, Inc.

Lin, S. Y., Chang, L. H., \& Su, S. P. (2007). A study of the relationship between event service quality and value and spectators' satisfaction and loyalty: An example of Chinese Professional Baseball League. Physical Education Journal, 40(1), 77-92. (In Chinese)

Lu, M. L., Lee, S. S., Tsai, W. C., \& Lin, C. W. (2013). A study on relationship among service quality, participant perceived value and behavioral intention in Adidas Cup Tennis Event. Journal of Chiao Da Physical Education, 6, 1-12. (In Chinese)

Millan, A., \& Esteban, A. (2004). Development of a multi-item scale for measuring customer satisfaction in travel agencies services. Tourism Management, 25(5), 533-546. http://dx.doi.org/10.1016/j.tourman.2003.07.002

Mullin, B. J., Hardy, S., \& Sutton, W. A. (2016). Sport marketing (4 ${ }^{\text {th }}$ ed.). Champaign, IL: Human Kinetics.

Murray D., \& Howat, G. (2002). The relationships among service quality, value, satisfaction, and future intentions of customers at an Australian sports and leisure center. Sport Management Review, 5(1), 25-43. http://dx.doi.org/10.1016/s14413523(02)70060-0

Musa, R., \& Kassim, R. M. (2013). Predictors and outcomes of sport event experiential value: Insights from formula one petronas Malaysia grand prix. International Journal of Management and Marketing Research, 6(1), 107-120.

Parasuraman, A., \& Grewal, D. (2000). Serving customers and consumers effectively in the twenty-first century: A conceptual framework and overview. Journal of Academy of Marketing Science, 28(1), 9-16. http://dx.doi.org/10.1177/0092070300281001 
Parasuraman, A., Zeithaml, V. A., \& Berry, L. L. (1988). A conceptual model of service quality and its implications for future research. Journal of Marketing, 49(4), 41-50. http://dx.doi.org/10.2307/1251430

Peng, H. N. (2016, February 15). The Williams Sisters competing at the 2017 Taiwan Open a good possibility.United Daily News, pp. B4. (In Chinese)

Petrick, J. F. (2002). Development of a multi-dimensional scale for measuring the perceived value of a service. Journal of Leisure Research, 34(2), 119-134.

Suharto, \& Sulistiyono (2015). The relationship of service quality on consumer satisfaction in shipyard industry. Modern Applied Science, 9(11), 247-257. http://dx.doi.org/10.5539/mas.v9n11p247

Tsuji, Y., Bennett, G., \& Zhang, J. (2007). Consumer satisfaction with an action sports event. Sport Marketing Quarterly, 16(4), 199-208.

Tu, Y. T., Li., M. L., \& Chih, H. C. (2013). An empirical study of corporate brand image, customer perceived value and satisfaction on loyalty in shoe industry. Journal of Economics and Behavioral Studies, 5(7), 469-483.

Yang, W., Tsai, W., \& Lin, C. (2014). A participation behavioral model for tennis tournaments. Journal of Sport and Recreation Management, 11(11), 1-19. http://dx.doi.org/10.6214/JSRM.1101.001 (In Chinese)

Yoshida, M., \& James, J. D. (2010). Customer satisfaction with game and service experiences: Antecedents and consequences. Journal of Sport Management, 24(3), 338-361. http://dx.doi.org/10.1109/icsssm.2006.320589

Yu, H. S., Zhang, J. J., Kim D. H., Chen, K. K., \& Huang, H. (2014). Service quality, perceived value, customer satisfaction, and behavioral intention among fitness center members aged 60 years and over. Social Behavior and Personality, 42(5), 757-768. http://dx.doi.org/10.2224/sbp.2014.42.5.757

Zeithaml, V. A. (1988). Consumer perceptions of price, quality, and value: A meansend model and synthesis of evidence. Journal of Marketing, 52, 2-22. http://dx.doi.org/10.2307/1251446

Zeng, S. R. (2016, February 11). WTA Taiwan Open. United Daily News, pp. A13. (In Chinese) 
